\title{
Effects of Oral Morphine on Cold Pressor Tolerance Time and Neuropsychological Performance
}

Charles S. Cleeland, Ph.D., Yoshio Nakamurn, Ph.D., Eric W. Howland, M.A.,

Nancy R. Morgan, R.N., M.S.N., Katherine R. Edwards, B.A., and Miroslav Backonja, M.D.

We inestigated the analgesic effects of escalating doses $(0.214,0.286,0.357$, and $0.429 \mathrm{mg} / \mathrm{kg})$ of oral morphine on tolerance to painful cold pressor in a double-blind, actioe placebo-controlled (diphenhydramine) study in 45 normal volunters. The highest tose of morphine administered is equivalent to the starting dose recommended by the Agency for Health Care Policy and Research for the management of cancer pain and acute postoperatiox pain. We assessed analgesia in terms of cold pressor tolerance time and selfreported ratings of pain intensity and unpleasantness.
KFy WORDS: Adterse effects; Analsesia; Cogrnitive performance; Cold pressor pain; Morphine; Motor performance

Opioid analgesics are recognized as the drugs of choice for moderate to severe pain (World Health Organization 1986; Jacox et al. 1994b). The effects of opioids on various aspects of pain perception have been extensively investigated, although the exact nature of these effects continues to be debated. Early studies by Beecher (1959) indicated that opioids did not significantly increase pain sensory thresholds. In light of these findings, Beecher proposed that opioids produce clinical analgesia by altering the unpleasantness of pain reactions rather than by altering the intensity of pain sensations.

Although Beecher's hypothesis has been historically

From the I'ain Research Group, Department of Veurology, University of Wisconsin Medical School, Madison, WI

Address correspondence to: Charles S. Cleeland, Ph.D., Pain Research Group, 1900 Lniversity Avenue, Madison, W1 53705-4013.

Received May 11, 1995; revised September 18, 1995; accepted September 28,1445
Subjects receiving the highest dose of oral morphine showed significantly higher tolerance time than subjects receiving diphenhydramine. Neither morphine or diphenhydramine significantly reduced ratings of pain intensity and umplasantness. Neuropsychological testing revealed that the two highest doses of inorphine impaired the episodic retriceal of a word list, but the same doses did not affect motor, perceptual, or attentional tasks.

[Neuropsychopharmacology 15:252-262, 1996]

influential, more recent studies suggest an alternative interpretation. There is now general agreement that previous negative results are largely due to the use of the pain threshold as a dependent measure in evaluating analgesia. Since the mid-1960s opioid analgesia has been routinely demonstrated in the laboratory with the use of other outcome measures, such as pain intensity ratings. As summarized by Gracely (1991), many studies demonstrated the effects of opioids on the sensory-intensity component of pain. Morphine and other opioids have reduced pain intensity produced by brief stimuli such as: electrical (Wolff et al. 1966; Parry et al. 1972; Buchsbaum et al. 1981; Cooper et al. 1986); thermal (Yang et al. 1979; Wolskee et al. 1981; Price et al. 1985; Cooper et al. 1986); or chemical (Cooper et al. 1986) stimuli and by continuous pains evoked by cold pressor (Posner et al. 1985; Jones et al. 1988) and tourniquet ischemia (Smith et al. 1966).

Contrary to what might be predicted from Beecher's hypothesis, it was shown that fentanyl reduced painful sensations but not the unpleasantness of pain in response to suprathreshold painful tooth pulp electrical stimula- 
tion (Gracely et al. 1979). The absence of fentanyl's effect on unpleasantness was attributed by these investigators to dysphoric mood changes produced by the drug. Price et al. (1985) also observed reductions in ratings of both pain intensity and unpleasantness in response to brief heat pulses when a high dose of intravenous morphine $(0.08 \mathrm{mg} / \mathrm{kg})$ was administered. Lower doses of morphine $(0.04$ and $0.06 \mathrm{mg} / \mathrm{kg})$ led to reductions in unpleasantness but not in the sensory intensity dimension of experimental pain.

An active placebo was not typically used to evaluate analgesia in those studies that demonstrated the analgesic effects of opioids. Diazepam as an active placebo was used in one study to produce side effects preceding the administration of fentanyl or inactive placebo (Gracely et al. 1982). The authors concluded that analgesia produced by fentanyl in their earlier study (Gracely et al. 1979) was not due to the detection of side effects that might have influenced subjective reports of pain intensity. This study illustrates the importance of using an active placebo in evaluating the analgesic efficacy of a particular drug that is known to produce noticeable side effects.

Behavioral or psychological methods are often used to control both acute and chronic pain. We have been investigating the effectiveness and mechanisms of hypnosis, distraction, and mood alteration in the laboratory with normal volunteers (Hodes et al. 1990; Zelman et al. 1991; Casey et al. 1994). Behavioral methods of pain control, if used at all, are rarely used independently of pharmacological treatments, especially when pain is severe (Cleeland 1988; Syrjala 1993). However, we know little about how pharmacological interventions such as those of morphine, the prototype drug for aggressive pharmacological management, might be further augmented by behavioral and psychosocial interventions. One of our research goals is to investigate combined effects of opioid analgesia and behavioral pain control methods on what we call "tonic" pain (Cleeland 1989; Zelman et al. 1991). Because morphine analgesic effects are determined by multiple factors (types, modalities, and intensities of pain), it is necessary to develop a laboratory paradigm that (1) produces relatively long-lasting pain; (2) is sensitive to opioid administration, and (3) is safe and repeatable in the laboratory.

Cold pressor is a laboratory model of tonic pain that has strong affective and autonomic components (Hilgard and Hilgard 1983). We have previously used cold pressor to investigate behaviorally induced mood effects on pain tolerance time (i.e., how long one can tolerate pain) and self-reported pain ratings (Zelman et al. 1991). We found that mood alterations affected pain tolerance time, but produced little change in pain ratings during cold pressor trials. In another study (Hodes et al. 1990), we used cold pressor to examine behaviorally induced attentional effects of pain ratings and pain tolerance. In this case, a distraction task used to manipulate attention reduced pain ratings in an earlier phase of cold pressor, but it did not change pain tolerance time. Our prior studies demonstrate the utility of cold pressor as a laboratory model of tonic pain. Cold pressor allows us to assess both pain tolerance time and subjective pain ratings. Various components of behavioral pain control methods (i.e., mood vs. distraction) have been shown differentially to affect pain tolerance time and intensity rating in the cold pressor task.

To investigate the combined effects of opioids and behavioral pain control methods on cold pressor pain, it is necessary to determine opioid effects on those responses (i.e., pain tolerance time and pain ratings) that have been shown to be modified by behavioral manipulations. Once morphine effects on these parameters are specified, we can pursue our investigation of combined effects on experimental tonic pain of opioid analgesics and behavioral methods of pain control.

The sedating effects of opioids may interfere with a patient's ability to meet the cognitive demands of a particular behavioral intervention method. It is thus crucial to determine how opioid administration could alter those cognitive functions necessary to behavioral methods of pain control (such as distraction and hypnosis). Opioid effects on cognitive tasks have not been extensively investigated in situations where their analgesic properties are also assessed. In one recent study designed to address morphine effects on cognitive and motor performance, a battery of cognitive tests was used to assess perception, memory, and language performance in subjects who were administered individually tailored steadystate drug infusions (Kerr et al. 1991). This study documented that delayed recall of information presented during morphine infusion was significantly impaired. The subjects also required a longer time to encode and process serially presented verbal information, and they had more difficulty in maintaining consistent low levels of force during morphine infusion. However, an assessment of response to painful stimulation was not included in this study.

Our primary objective was to document the analgesic effects of increasing doses of orally administered morphine on experimental pain induced by the cold pressor. The specific goal was to determine a morphine dose sufficient to produce changes in pain tolerance time and pain rating in the cold pressor test with minimal clinical side effects in normal volunteers. Outcome measures for analgesia included pain tolerance time and self-report ratings of pain intensity and unpleasantness. Although morphine effects have been extensively documented, most studies evaluated analgesia without using an active placebo. Thus, we used diphenhydramine as an active placebo in our study to evaluate the extent to which orally administered morphine alters pain perception. Diphenhydramine causes similar side effects as those produced by opioids without known analgesic effect. 
A subset of subjects in the present experiment were also given neuropsychological tests designed to examine side effects of morphine on cognitive and motor performance. All the subjects receiving the highest dose and seven out of eight subjects receiving second highest dose completed the battery. The tests were designed to assess fine motor coordination, perceptual-motor coordination, verbal memory recall, and complex cognitive (i.e., mental arithmetic) performance. We postulated that morphine would impair episodic verbal memory recall, on the basis of previously reported findings (Kerr et al. 1991). If episodic verbal memory is impaired by morphine, the use of behavioral manipulations heavily dependent on memory components might be more difficult to implement in both the laboratory and clinic.

We also examined the possibility of morphine-induced mood effects in normal healthy subjects. A number of studies have investigated the effects of morphine administration on mood, but these were most often performed with clinical patients who were given morphine for pain treatment. Some of these clinical studies have shown an increase in positive mood (Kaiko et al. 1981), but others found no evidence for mood change (Glynn et al. 1988). As mood changes can affect tolerance time (Zelman et al. 1991), it was important to assess mood changes due to morphine and diphenhydramine to clarify the interpretation of changes in tolerance time.

\section{METHODS}

\section{Subjects}

Twenty-four women and 21 men participated in the study. All were healthy, right-handed subjects ranging in age from 18 to 37 . All aspects of the study were approved by the University of Wisconsin Hospitals and Clinics Institutional Review Board. Subjects were recruited via campus newspaper, and an initial screening was conducted over the telephone. Subjects were paid $\$ 10.00$ per hour for their participation. A Medical History Form was initially obtained for each subject. Subjects also completed the SCL-90R as a way of screening for psychological disturbance (Derogatis 1983). No subject was excluded on the basis of their SCL-90-R score.

Other exclusion criteria included: age less than 18 , inability to read, write, or understand English, chronic pain of any type, high blood pressure, epilepsy or history of any type of convulsions, current use of cold or allergy medications, reported use of illicit drugs, hospitalization for psychiatric reasons, ongoing psychotherapy, previous involvement in study of morphine and pain, frequent cold water activity, and left-handedness. In addition, subjects underwent a baseline cold pressor trial on day 1 . Subjects maintaining the arm in the cold pressor less than 30 seconds or longer than $41 / 2$ minutes were not considered for day 2, because they were unlikely to manifest analgesic effects of morphine within the preset time limit adopted in the study. Our of 50 subjects recruited, five subjects were excluded based on the day 1 cold pressor criterion, and the remaining 45 subjects completed the study.

\section{Study Design}

The study used a two-session design with the sessions at least 48 hours apart. Experimental sessions were scheduled to start at either 9:00 a.m. or 1:00 p.m. On day 1, baseline measurements were taken. Each subject placed the left arm in the cold pressor with the instruction to remove the arm from the cold pressor when he or she could not tolerate it any longer. The upper limit for the duration of cold pressor (unknown to subjects) was set at five minutes (300 s). Subjects were asked to remove the arm from the water if they had not already done so after five minutes. Subjects who were able to undergo the cold pressor for between 30 and 270 seconds were scheduled for day 2 . The subjects were then instructed (1) not to eat at least 1 hour before the experiment on day 2 and (2) not to use any recreational drug or to drink alcohol 24 hours before the experiment.

On day 2, about 60 minutes prior to the cold pressor test, subjects ingested either a single dose of morphine or placebo. Although there is interindividual variability, 60 minutes is a reasonable approximation of time to peak effect for oral morphine (Glare and Walsh 1991). Morphine doses included $0.214,0.286,0.357$, and $0.429 \mathrm{mg} /$ $\mathrm{kg}$. The active placebo was a $0.357-\mathrm{mg} / \mathrm{kg}$ dose of diphenhydramine. Medications were administered in doubleblind placebo-controlled fashion as liquid preparations for each dose as provided by the University of Wisconsin Hospital pharmacy. Morphine was administered in increasing doses to address the concerns from our Institutional Review Board regarding potential clinical side effects. Our highest dose is the one that has been proposed by the Agency for Health Care Policy and Research (AHCPR) Guidelines for Management of Cancer Pain (30 mg/70 kg) as the starting dose for the management of moderate to severe pain due to cancer (Jacox et al. 1994b) and also in the management of acute postoperative pain (Acute Pain Management Guideline Panel 1992). The pharmacy randomly assigned subjects to either placebo or to a particular morphine dose. At conclusion of the study, 31 subjects had received oral morphine, whereas 14 subjects had received diphenhydramine. Sixty minutes after ingesting the drug, subjects performed the cold pressor task. Subjects completed the Mood Adjective Check List (MACL) (Nowlis 1965) at three time points: prior to drug administration, prior to cold pressor, and following cold pressor. Blood pressure and pulse rate were measured at baseline and monitored throughout the study period on day 2 .

Subjects remained at the study site for 3 hours from the time of ingestion of either drug. The first 18 subjects 
did sedentary tasks until the 3 hours had passed. The latter 27 subjects were given a battery of neuropsychological tests. Upon the completion of a study session, all subjects were escorted and sent home by taxi according to a previously signed postexperimental agreement (not to drive or consume alcohol for the remainder of the day).

\section{Pain and Symptoms Assessment}

"Pain intensity" ratings and ratings of the "Unpleasantness of pain" were reported by a subject every 15 seconds while the subject's arm was in the cold pressor. Pain ratings were obtained on a 0 to 10 scale, in which 0 was anchored at "no pain at all" and 10 at "pain as bad as you can imagine." Unpleasantness was also rated on a 0 to 10 scale, with 0 anchored at "not unpleasant at all" and 10 at "as unpleasant as you can imagine." After the cold pressor test on day 2 , subjects were administered the post experimental questionnaire designed to assess the cold pressor experience. They were also asked openended questions about any side effects and sensations they might have experienced or coping strategies they might have used.

\section{Neuropsychological Testing}

Neuropsychological testing in this study included the following tests: Rey Auditory Verbal Learning Test (AVLT) (Lezak 1983; Wiens et al. 1988), Peghoard (Davison and Reitan 1974), Trail-Making Test (Heaton et al. 1994), and Paced Auditory Serial Addition Test (PASAT) (Gronwall 1977). The tests were given to the 27 subjects in the order in which they are listed and were completed by each subject approximately $11 / 2$ hours after the ingestion of the study drug.

Memory and Learning Assessment. The Rey Auditory Verbal Learning Test (AVLT) is typically used to (1) measure immediate memory; (2) provide a learning curve; (3) reveal learning strategies or their absence; (4) elicit retroactive and proactive interference tendencies; (5) reveal tendencies toward confusion or confabulation; and finally (6) measure retention after a time lapse. Each recall trial consists of an auditory presentation of 15 words, followed by a subject's attempt to reproduce the words presented. The recall trial was repeated five times in the present assessment (Recall Trials 1 through 5). After the completion of the fifth recall trial, the second set of 15 words was presented as a distractor and followed by a recall of that second list. The sixth recall trial was a free recall of the first line of 15 words presented (Recall Trial 6), without presenting the preceding word list. It typically takes about 10 minutes to complete the six recall trials. Retention was then assessed after 30 minutes in a free recall task in which the subject was then asked to remember the first list presented (Delayed Recall Trial). Finally, recognition memory was as- sessed by presenting the subject with a mixed list of new words and words previously presented on the first list and asking the subject to distinguish between the two.

Perceptual-Motor Coordination. First, the pegboard task was used to examine the speed of fine motor coordination. The subject, while being timed and using a specific sequence, is asked to place 25 one-inch long identical metal notched pegs into coordinating holes on a 4 -inch board. Then the Trail-Making Test was used to measure perceptual-motor coordination. A subject was presented with a sheet of paper that had printed dots representing (1) number or (2) number and letter. The subject was asked to connect the number (dots) or number/letter (dots) in sequence while being timed. An example of the latter would be, "connect the number/letter dots in order, but alternating between a number, a letter, a number, a letter, as in 1,A,2,B,3,C."

Sustained Attention and Mental Arithmetics. The Paced Auditory Serial Addition Test (PASAT) was used to assess sustained attention and information-processing speed. It was originally devised to measure the acute effects of minor head injury (Gronwall 1977). A cassette tape presented 60 numbers at a rate of one number every 3 or 2 seconds (each subject was administered the 3-s version followed by the 2-s version). The subject was asked to add the current number to the one just prior and respond aloud. For example, given the string 3, 1, 4, 2, the subject would reply " $4,5,6$."

\section{Analysis of Neuropsychological Test Data}

Performance scores from these neuropsychological tests of motor function and attention were compared with ageappropriate norms and transformed into $t$ scores. The normative data are obtained from Wiens et al. (1988) and the Neuropsychology Clinic in the Department of Neurology at the University of Wisconsin Medical School (Beardsley et al. 1978a, 1987b). Performance scores were analyzed by analysis of variance (ANOVA), with escalating doses of morphine as between-subject factor and test-related factors as within-subject factor. The use of $t$ scores in expressing neuropsychological performance allowed us to evaluate how performance following drug administration compared to the mean of the normative data set.

\section{Analysis of Pain Tolerance Time}

A variable was created by subtracting the tolerance time on day 1 from the tolerance time on day 2 for each subject. This variable was used as a measure of the extent to which the pharmacological interventions given on day 2 extended the tolerance times in the cold pressor task. Because the distribution based on the raw tolerance time scores revealed somewhat skewed distributions and unequal variances among the groups, the change scores were 
Table 1. Difference in Pain Intensity Rating"

\begin{tabular}{lcccc}
\hline & $\begin{array}{c}\text { Pain Intensity } \\
\text { (at 15 s) }\end{array}$ & $\begin{array}{c}\text { Pain Intensity } \\
\text { (at 30 s) }\end{array}$ & $\begin{array}{c}\text { Pain Intensity } \\
\text { (at 45 s) }\end{array}$ & $\begin{array}{c}\text { Pain Intensity } \\
\text { (at 60 s) }\end{array}$ \\
\hline Diphenhydramine & $0.21(1.31)$ & $0.00(1.24)$ & $-0.31(1.03)$ & $0.00(1.58)$ \\
$0.214 \mathrm{mg} / \mathrm{kg}$ & $1.00(2.00)$ & $0.83(1.72)$ & $0.33(1.97)$ & $0.10(1.67)$ \\
$0.286 \mathrm{mg} / \mathrm{kg}$ & $0.38(.74)$ & $0.79(.91)$ & $0.71(.95)$ & $0.38(.75)$ \\
$0.357 \mathrm{mg} / \mathrm{kg}$ & $0.00(.93)$ & $0.25(1.58)$ & $-0.17(1.17)$ & $-0.17(1.33)$ \\
$0.429 \mathrm{mg} / \mathrm{kg}$ & $-0.50(2.67)$ & $-0.63(2.26)$ & $-0.63(2.13)$ & $-0.83(1.33)$ \\
\hline
\end{tabular}

Dax 2 rating - day I rating at $15,30,45$, and 60 seconds after the start of the Cl' task

Standard deviations in parentheses. No significant differences among the groups.

log-transformed to satisfy the assumptions necessary to perform the ANOVA.

\section{Analysis of Pain Ratings}

Because the first minute of the cold pressor test is the time period in which data from most subjects are available and ratings are expected to be lower (Hodes et al. 1990), subjective ratings during the first 60 seconds were, analyzed. For both pain intensity and unpleasantness ratings, day 1 and day 2 ratings were analyzed by repeatedmeasures ANOVA separately at each point $(15,30,45$, and $60 \mathrm{~s}$ ). Unpleasantness ratings from day 1 were not collected for the first seren subjects (three from the control group, four from the $0.214-\mathrm{mg} / \mathrm{kg}$ group).

\section{RESULTS}

We assessed cold pressor pain in terms of several different measures (i.e., tolerance time, unpleasantness rating, and pain rating), each designed to measure conceptually different aspects or dimensions of pain.

\section{Effects of Morphine on Pain Intensity and Unpleasantness Ratings}

Pain intensity and unpleasantness ratings on day 1 and day 2 during the first $60 \mathrm{~s}$ in the cold pressor session were analyzed separately using a group (five levels, active placebo and four morphine dose levels) $\times$ day (two levels, day 1 and day 2) repeated-measures A.VOVA at each of the four successive time points $(15,30,45$, and 60 s). The results revealed no significant differences among the groups, indicating that morphine reduced neither ratings of pain intensity nor unpleasantness compared to an active placebo. In addition, there was no main effect for day, indicating that neither morphine nor diphenhydramine produced a significant change in ratings of pain intensity or unpleasantness.

Table 1 shows change scores in pain intensity ratings during the first $60 \mathrm{~s}$ of the cold pressor task. Change scores in pain unpleasantness ratings are shown in Table 2. As seen in Table 1, at the highest dose of morphine, pain intensity ratings during the first $60 \mathrm{~s}$ tended to decrease slightly. However, these differences were not statistically significant when the highest dose group was analyzed separately.

\section{Effects of Morphine on Pain Tolerance Time}

Morphine was predicted to increase pain tolerance (measured in terms of the time the subject was able to keep his or her arm in the cold pressor). Figure 1 shows difference tolerance time data ( $\log$ transformed) from the five different conditions.

Subjects who received morphine were able to keep their arm in the cold pressor task longer than those who received diphenhydramine. This observation was supported by a planned comparison between the control group and the combined morphine groups that showed that the increases in the tolerance time were significantly greater for the morphine groups than for the control group $(t=2.638, \mathrm{df}=40, p<.05)$. An ANOVA on

Table 2. Difference in Pain Unpleasantness Rating:t

\begin{tabular}{lcccc}
\hline & $\begin{array}{c}\text { Unpleasantness } \\
\text { (at 15 sec) }\end{array}$ & $\begin{array}{c}\text { Unpleasantness } \\
\text { (at 30 sec) }\end{array}$ & $\begin{array}{c}\text { Unpleasantness } \\
\text { (at 45 sec) }\end{array}$ & $\begin{array}{c}\text { Unpleasantness } \\
\text { (at 60 sec) }\end{array}$ \\
\hline Diphenhydramine & $-0.09(1.22)$ & $-0.09(.70)$ & $-0.09(.83)$ & $-0.14(.69)$ \\
$0.214 \mathrm{mg} / \mathrm{kg}$ & $-0.33(1.15)$ & $0.00(2.00)$ & $-1.00(2.00)$ & $-0.83(1.44)$ \\
$0.286 \mathrm{mg} / \mathrm{kg}$ & $0.25(.46)$ & $0.71(1.11)$ & $0.43(1.72)$ & $-0.50(.58)$ \\
$0.357 \mathrm{mg} / \mathrm{kg}$ & $-0.75(1.28)$ & $0.38(1.60)$ & $-0.50(1.64)$ & $-0.17(2.32)$ \\
$0.429 \mathrm{mg} / \mathrm{kg}$ & $0.00(2.14)$ & $0.00(1.60)$ & $0.00(1.41)$ & $-0.50(1.87)$ \\
\hline
\end{tabular}

"Dav 2 rating - das 1 rating at 15,30, 45, and fol seconds after the start of the Cl' task.

Standard deviations in parentheses. No significant differences among the groups 


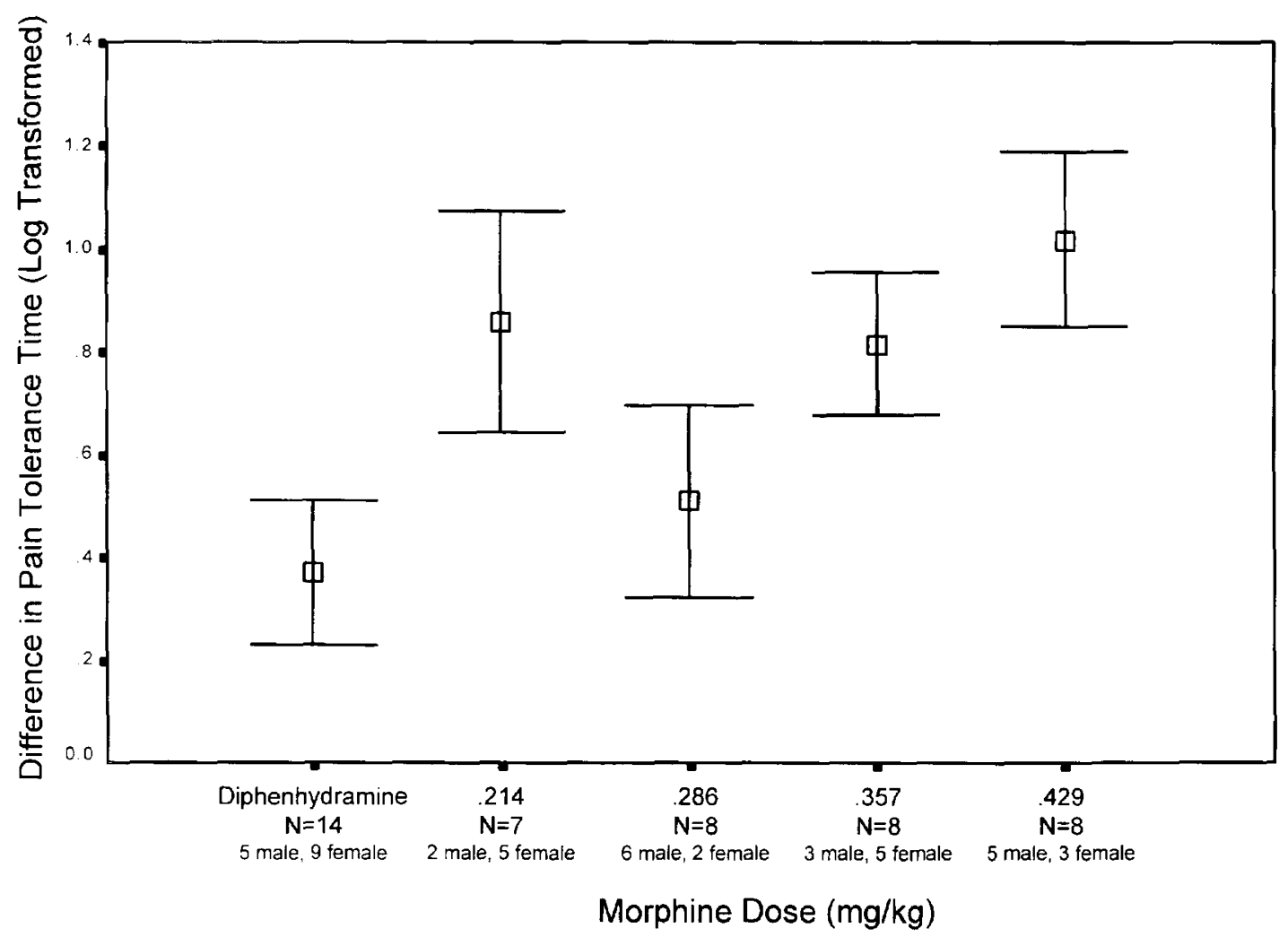

Figure 1. Effect of morphine on tolerance time in cold pressor. Boxes, mean change in pain tolerance time (log transformed) for each dose condition. Error bars, \pm 1 standard error around the mean.

the log-transformed change scores was performed to examine differences between the groups assigned to the different doses of morphine and the diphenhydramine group. Pairwise multiple comparisons (Tukey-HSD test with significance lev'el set at .05) revealed that the 0.429$\mathrm{mg} / \mathrm{kg}$ dose condition was the only dose significantly different from the diphenhydramine condition, demonstrating that $0.429 \mathrm{mg} / \mathrm{kg}$ of morphine extended the tolerance time significantly longer than did diphenhydramine.

Because the therapeutic efficacy of a drug may vary as a function of gender (as suggested in Merkatz and Temple 1993), a post hoc comparison involving gender was performed for the morphine dose level $(0.429 \mathrm{mg} /$ $\mathrm{kg}$ ) that was found to increase tolerance time in the cold pressor. An ANOVA on tolerance time showed no significant difference between the two groups based on gen$\operatorname{der}(F(1,6)=0.35, \mathrm{MS}=.26, p<.58)$. However, given the small sample size ( $n=8$, five males vs. three females), the estimated power was small (0.084), although Eta squared as an estimated measure of effect size was also very small $\left(\eta^{2}=0.056\right)$.

\section{Clinical Side Effects from Morphine}

Table 3 documents the types and frequencies of clinical side effects reported in the dav 2 postexperimental questionnaire completed by all the subjects tested. As seen in Table 3, diphenhydramine produced side effects similar to those produced by morphine. No vomiting or severe nausea were observed. Because of the open-ended nature of these responses, no statistical test was performed.

\section{Effects of Morphine and Diphenhydramine on Mood}

The present study and its design allowed us to evaluate the degree to which the study drugs influenced the subjects' reported mood. As described, the subjects' mood was assessed by MACL (1) prior to drug ingestion and (2) after drug administration, but before cold pressor. Data based on MACL measures were analyzed by a time (two levels, pre- and post-drug administration) $\times$ group (five levels, diphenhydramine and four morphine dose levels) repeated-measures ANOVA. Neither the main effect of group nor the interaction effect on mood was statistically significant, indicating that morphine-induced mood changes were not statistically different from those changes produced by diphenhydramine.

However, a number of MACL items did show significant changes after drug administration regardless of drug group. Subjects in all drug groups reported that they felt more fatigued, less anxious, less fearful, less in control, less elated, less energetic, and less motivated. These changes are consistent with clinical side effects reported in the post experimental questionnaire completed by 
Table 3. Self-Reported Side Effects from Diphenhydramine and Oral Morphine $e^{\text {ll }}$

\begin{tabular}{|c|c|c|}
\hline Symptoms & $\begin{array}{l}\text { Diphenhydramine } \\
\qquad(n=14)\end{array}$ & $\begin{array}{c}\text { Morphine } \\
(n=31)\end{array}$ \\
\hline Tired, fatigued & $13\left(93^{\circ} 0\right)$ & $19\left(61 \%^{\circ}\right)$ \\
\hline Mental clouding & $1\left(7^{\prime \prime} 0\right)$ & $9\left(29^{\circ}\right)$ \\
\hline Dizzy & $3\left(21^{\prime \prime} 0\right)$ & $3\left(10^{\prime \prime}\right)$ \\
\hline Headache & $2\left(14^{\prime \prime} 0\right)$ & $2\left(6^{\circ} \%\right)$ \\
\hline Dry mouth & 0 & $2\left(6^{\circ} \%\right)$ \\
\hline Nausea & 0 & $3(10 \%)$ \\
\hline Relaxed & $\left.1\left(7^{\prime \prime}\right)\right)$ & $8(26 \%)$ \\
\hline Paresthesia & $2\left(14^{\prime \prime} 0\right)$ & $4(13 \%)$ \\
\hline Anxious & 0 & $2\left(6^{\prime \prime}\right)$ \\
\hline Slurred speech & 0 & $1\left(3^{\circ} \%\right)$ \\
\hline Melancholy feeling & 0 & $1\left(3^{\circ}\right)$ \\
\hline Blurred rision & 0 & $1\left(3^{\circ} \omega\right)$ \\
\hline Vosymptoms & 0 & $2\left(6^{\circ} \%\right)$ \\
\hline No response (missing) & 0 & $3\left(10^{\circ} n\right)$ \\
\hline
\end{tabular}

"Values in Table represent the number of subjects in each group who produced written comments on drug side effects in response to the guestion "What sensations did you experience following the drug administration?" Numbers in parentheses are the proportions of the subjects who reported the corresponding side effect sensations

Based on retrospective self-reports of side effects.

the subjects on day 2. Some changes can be interpreted as "positive" (less anxious, less fearful), but other changes may be interpreted as "negative" (more fatigued, less in control, less energetic, less elated, less motivated). Thus, it is difficult to specify the degree to which positive and negative mood changes were produced by both morphine and diphenhydramine. Consequently we cannot determine how mood changes affected the efficacy of morphine analgesia.

\section{Effects of Morphine on Neuropsychological Tests}

Overall, the AVLT task was affected by opioid administration (0.357-and $0.429-\mathrm{mg} / \mathrm{kg}$ doses), but there were no significant effects of morphine on other tasks.

AVLT (Word Recall Task). Recall Trials 1 through 5 were analyzed by repeated-measures ANOVA with a mixed design. There was no significant dose group $x$ recall trial interaction or main effect of either factor. Recall of words on the distracter list did not differ among the five groups. Recognition memory performance based on the first word list at the end of a neuropsychological testing session did not differ among the groups. The data also showed that subjects made virtually no errors in the recognition test.

Figure 2 show's performance based on Recall Trial 6 and Delayed Recall Trial, respectively. We found that higher doses of morphine $(0.347$ and $0.429 \mathrm{mg} / \mathrm{kg})$ produced recall impairment in the word recall task at the time of Recall Trial 6 and Delayed Recall Trial. These observations were confirmed by univariate ANOVA on
Recall Trial 6 and the Delayed Recall Trial $(F(4,22)=$ $2.87, p<.05$ for Recall Trial 6 and $F(4,22)=3.53, p<.05$ for the Delayed Recall Trial). Separate univariate analyses were performed because the Recall 6 and Delayed Recall trials were designed to measure conceptually different aspects of memory performance. The major source of differences among the five groups was seen in the complex contrast between the two groups with higher doses of morphine and the other three groups. This was tested by contrast analysis, which showed a significant difference between the higher dose groups $(0.357$ and $0.429 \mathrm{mg} / \mathrm{kg})$ and the other three groups $(t=3.02, \mathrm{df}=$ $22, p<.01$ for Recall Trial 6 and $t=3.70, \mathrm{df}=22, p<$ .005 for the Delayed Recall Trial). These findings demonstrate that morphine can impair episodic retrieval of verbal information in the delayed memory task, but not retrieval from short-term or immediate memory (memory immediately after the word list was read by the experimenter).

Data from the Pegboard, Trail-Making, and PASAT test are presented in Table 4. Performance scores ( $t$ score) for each task are a function of escalating doses of oral morphine

Pegboard (a simple motor coordination task). Data from the Pegboard task in Table 4 showed that there was no difference among the five groups in terms of the time to complete this motor coordination task. There was no difference in performance between the dominant and nondominant hand (50.3 vs. 52.3 ).

Trail-Making Test (a perceptual-motor task). Data from the Trail-Making Test in Table 4 showed that there was no difference among the five groups in terms of the time to manually connect printed letters or numbers in sequential orders. Even during the more difficult version, subjects did not show signs of deterioration from morphine compared to the diphenhydramine group.

PASAT (a sustained attention task). Data from the PASAT in table 4 indicated that there was no difference in the accuracy of mental arithmetic among the five groups. The time interval ( 3 s vs. 2 s) in the PASAT produced no difference in PASAT accuracy $(54.9$ for 3-s interval vs. 55.2 for $2-s$ interval, both expressed as $t$ scores). Our data indicate that the accuracy of cognitive operation (adding two numbers) was not compromised by oral morphine compared with diphenhydramine.

This study did not include a no-drug group. However, the use of $t$ scores allows us to make a general statement about how performance was affected by the drugs in the study. In the normative data set $t$ scores of 50 represent the average performance of normal subjects (with a standard deviation of 10).

Then $t$ score data from the Pegboard, Trail-Making, and PASAT tests were compared with $t$ scores from the normative data set. Data presented in Table 4 indicate 


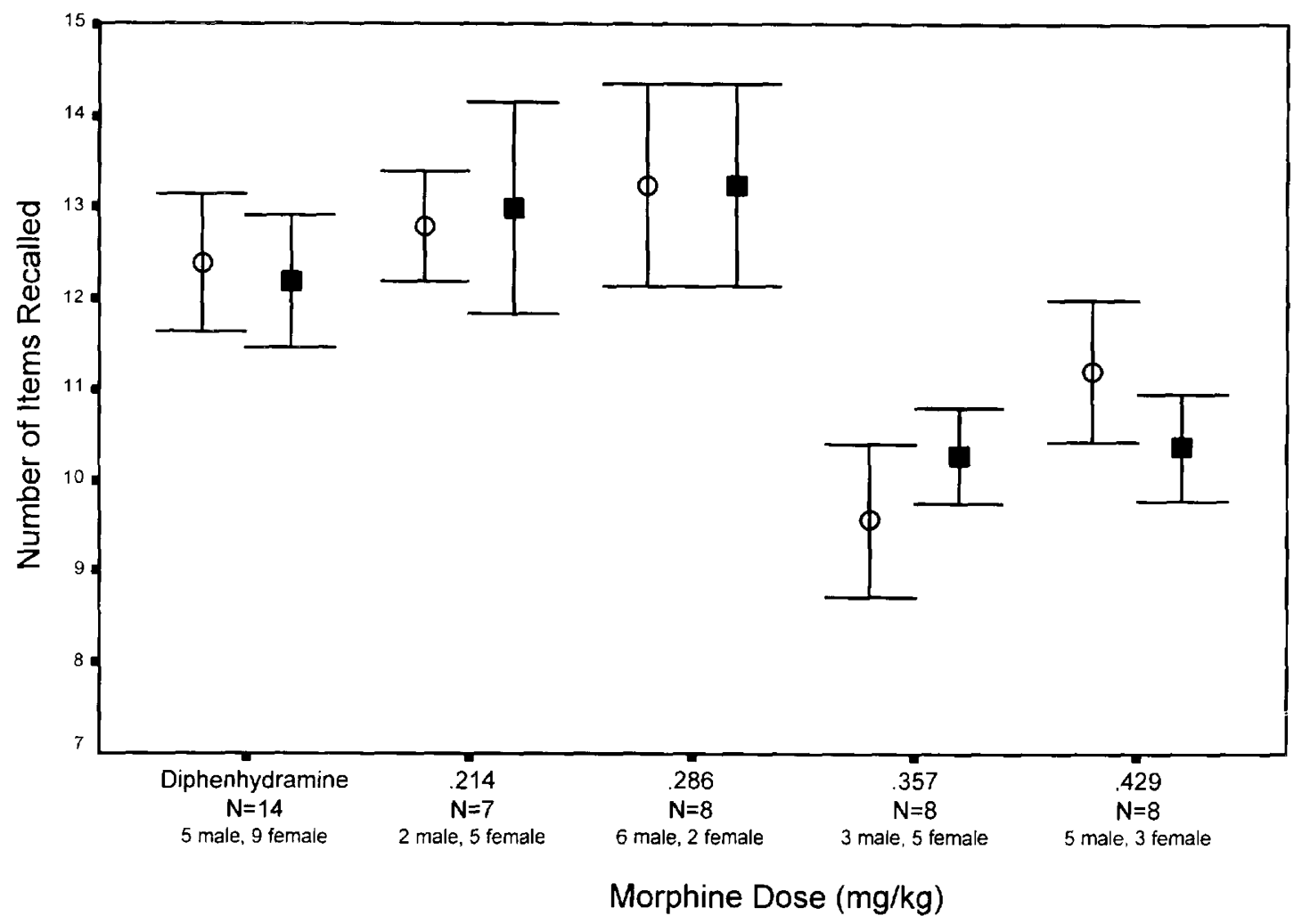

Figure 2. Effects of morphine on memory (from AVLT). Circle's, number of items recalled in AVLT Recall Trial 6 (a free recall of the 15 items presented in recall trials 1 through 5 following the presentation and recall of a distractor word list). Boxes, number of items recalled in the AVLT Delayed Recall Trial (a free recall of the 15 items presented in Recall Trials 1 through 6 , 30 minutes after recall trial 6). Error bars, \pm 1 standard error around the mean.

that performance scores in most cells are close to 50 , reflecting that these subjects' performances were comparable to the norm-based average performance. A onesample t-test was separately performed for each score below 50, but none produced significant results. Thus, our data suggest that neither morphine nor diphenhydramine in the doses used here compromised neuropsychological performance relative to the normative data set.

Table 4. Drug Effects on Motor, Perceptual-Motor, and Vigilance taskst

\section{$\mathrm{mg} / \mathrm{kg}$}

\begin{tabular}{|c|c|c|c|c|c|c|}
\hline & Diphenhydramine & 0.214 & 0.286 & 0.357 & 0.429 & $\begin{array}{c}\text { Morphine } \\
\text { Combined }^{b}\end{array}$ \\
\hline $\begin{array}{l}\text { Total } N \text { in group } \\
\text { (male, female) }\end{array}$ & $\begin{array}{c}14 \\
(5,9)\end{array}$ & $\begin{array}{c}7 \\
(2,5)\end{array}$ & $\begin{array}{c}8 \\
(6,2)\end{array}$ & $\begin{array}{c}8 \\
(3,5)\end{array}$ & $\begin{array}{c}8 \\
(5,3)\end{array}$ & $\begin{array}{c}31 \\
(16,15)\end{array}$ \\
\hline $\begin{array}{l}N \text { for Tests } \\
\text { (male, female) }\end{array}$ & $\begin{array}{c}5 \\
(1,4)\end{array}$ & $\begin{array}{c}3 \\
(1,2)\end{array}$ & $\begin{array}{c}4 \\
(3,1)\end{array}$ & $\begin{array}{c}7 \\
(2,5)\end{array}$ & $\begin{array}{c}8 \\
(5,3)\end{array}$ & $\begin{array}{c}22 \\
(11,11)\end{array}$ \\
\hline $\begin{array}{l}\text { Test type } \\
\text { Pegboard }\end{array}$ & & & & & & \\
\hline $\begin{array}{l}\text { Dominant hand } \\
\text { Nondominant hand }\end{array}$ & $\begin{array}{l}48.13(10.62) \\
52.67(6.55)\end{array}$ & $\begin{array}{l}55.18(5.83) \\
56.48(10.43)\end{array}$ & $\begin{array}{l}52.43(8.34) \\
56.25(5.73)\end{array}$ & $\begin{array}{l}50.93(7.12) \\
47.62(12.48)\end{array}$ & $\begin{array}{l}48.11(10.85) \\
52.61(12.42)\end{array}$ & $\begin{array}{l}50.76(8.54) \\
52.21(11.12)\end{array}$ \\
\hline $\begin{array}{l}\text { Trail-making task } \\
\text { Simple } \\
\text { Complex } \\
\text { PASAT (3-s intervals) } \\
\text { PASAT (2-s intervals) }\end{array}$ & $\begin{array}{l}53.64(8.60) \\
62.13(7.90) \\
54.70(6.84) \\
58.20(4.17)\end{array}$ & $\begin{array}{l}55.76(4.30) \\
65.63(7.10) \\
57.22(.71) \\
58.82(6.45)\end{array}$ & $\begin{array}{l}58.30(1.63) \\
58.20(6.60) \\
48.92(5.33) \\
53.14(11.95)\end{array}$ & $\begin{array}{l}54.81(5.35) \\
60.80(8.67) \\
56.01(3.89) \\
54.82(4.74)\end{array}$ & $\begin{array}{l}52.92(7.51) \\
57.57(9.96) \\
56.34(3.94) \\
53.36(7.12)\end{array}$ & $\begin{array}{l}54.88(5.74) \\
59.81(8.55) \\
55.00(4.73) \\
54.53(7.16)\end{array}$ \\
\hline
\end{tabular}

"Values are expressed in $T$ score. Standard deviations in parentheses. No significant differences among doses.

"Morphine Combined group includes all morphine dose conditions.

Test type $=$ type of neuropsychological test. 


\section{DISCUSSION}

Subjects who received oral morphine (when all dose levels are examined together) showed increased pain tolerance time in the cold pressor in comparison with the control subjects receiving the active placebo (diphenhydramine). The morphine dose of $0.429 \mathrm{mg} / \mathrm{kg}$ produced a significantly longer tolerance than did the active placebo (see Figure 1). Although a significant increase in tolerance time in the cold pressor task was observed, there were no significant reductions in either pain intensity or unpleasantness ratings during cold pressor for either the morphine or diphenhydramine groups. This finding differs from earlier studies examining the effects of intravenously administered morphine on phasic pain. For example, Price and his colleagues (Price at al. 1985) reported that morphine reduced subjective ratings of both pain intensity and unpleasantness caused by brief phasic painful heat pulses.

There are several differences between our study and other earlier studies. First, we evaluated morphine analgesia by comparing its effects with those produced by an active placebo. The side effects produced by diphenhydramine might have obscured reductions in intensity and unpleasantness ratings. However, this possibility is unlikely because there was no significant main effect on either of these ratings when the morphine and diphenhydramine groups were combined.

Second, cold pressor was used as the painful stimulation in our study while brief heat pulses or electrical shocks were used in most of the earlier studies. To date, there have been only two studies that evaluated opioid effects on cold-induced pain in normal volunteers, but neither of these studies used an active placebo to evaluate analgesia. Posner et al. (1985) found that dipipanone reduced pain intensity scores compared with an inactive placebo. Similarly, Jones et al. (1988) found that morphine produced significant reduction in both peak pain intensity and area under curve pain intensity (AUC-PI) compared with placebo during the cold pressor task.

Both Posner et al. (1985) and Jones et al. (1988) set relatively short upper time limits for the cold pressor task ( 3 and 2 minutes, respectively). These limits may have been set to increase the number of subjects completing the cold pressor and to simplify the analysis of pain intensity ratings. However, this meant that there was no measure of pain tolerance in those studies. Because the AUC-PI as an outcome measure combines pain intensity and tolerance time into a single index, it is difficult to compare our results directly with their findings because of the differences in the cold pressor procedures and outcome measures.

Despite the differences that may result from various experimental designs (e.g., types of pain, route of drug administration), our study demonstrates that tolerance time in the cold pressor task is correlated to opioid ad- ministration. This effect is observed at a clinically recommended starting dose for severe pain. This dose did not produce clinically significant side effects in normal volunteers.

Morphine and diphenhydramine produced similar changes in mood as assessed by the MACL. These mood changes included (1) reductions in ratings of positive mood items (less energetic, less elated, less motivated, less in control); (2) greater ratings of fatigue; and (3) reductions in ratings of anxiety and fearfulness. As similar mood changes also followed the administration of diphenhydramine, oral morphine's greater analgesic effect on tolerance time is not indirectly mediated by mood changes induced by morphine. In patient samples, Kaiko et al. (1981) found morphine-induced positive mood changes when a multi-item test instrument was used (Lasagna et al. 1955), and Glynn et al. (1988) did not find any evidence for morphine-related mood changes when using a single visual analog item to assess mood. The present study was not designed to examine the question of whether mood alteration with morphine is different in normal subjects versus patients with pain.

Morphine caused performance deficits in some aspects of a verbal memory test. There were significant performance deteriorations in the auditory verbal memory test that involved delayed recall performance. Delayed recall and the recall following the presentation of the distractor list were both reduced by the effective analgesic dose of oral morphine $(0.429 \mathrm{mg} / \mathrm{kg})$. The morphine dose of $0.357 \mathrm{mg} / \mathrm{kg}$ also produced performance deficit in these memory trials, even though this dose level in itself failed to produce a significant increase in the tolerance time in the cold pressor task. It should be noted that (1) the target word list was not read by the experimenter for Recall Trial 6 and Delayed Recall (the list was not read each time prior to Recall 1 through Recall $5)$ and that (2) the recall of the distractor list was required before the administrations of Recall 6 and Delayed Recall. These factors suggest that although morphine did not affect the retrieval from short-term or immediate memory, it impaired the retrieval of verbal information from long-term memory. The effect of delayed recall documented here is the result of a single dose of oral morphine. It would be important to establish whether similar effects are observed in patients who experience pain and take morphine on a scheduled basis.

In contrast, morphine had no effect on complex motor, perceptual-motor coordination, and complex mental calculation tasks compared to diphenhydramine. The motor task required rapid fine motor coordination, yet no effect of morphine was found, even at the highest dose. The perceptual-motor coordination task may have been too easy for the group of subjects tested (university students at our institution). These findings are consistent with recent studies that document the lack of morphine effects on psychomotor tasks (Zacny et al. 1994). 
The present findings documenting memory deficit and the lack of motor and attentional impairment remain preliminary for several reasons. First, it might be necessary to include a more sensitive control condition against which drug side effects can be compared. Diphenhydramine is an excellent active placebo control for analgesics per se, but it does cause side effects. When the primary goal is to assess the cognitive side effects of morphine, it might be appropriate to use an inactive placebo.

Second, our findings may be qualified by statistical considerations. We calculated both estimates of effect size and power for the neuropsychological outcome measures that produced nonsignificant results. Although the statistical power estimated for each of these analyses tended to be small (no greater than .184), the estimate of effect size (e.g., Eta squared) also tended to be small (no greater than .109). The small estimates of effect size observed suggest that any differences found by greatly increasing sample size may be trivial. The only exception to this pattern was PASAT with a 3 -s interval (power $=.537, \eta^{2}=.281$ ).

In further exploring the negative findings (absence of oral morphine effects on the motor, perceptual-motor coordination, and attentional tasks), the sensitivity of each task may need to be further examined. Impairment in maintaining consistent low-level force in a motor task was documented by the Kerr et al. study (1991). The level of task difficulty may be an important critical variable in revealing motor impairment. In the present study the two different levels of task difficulty in the Trail-Making Test were not differentially affected by the escalating doses of oral morphine. This suggests that it is desirable to include a wider range of task difficulty (or tasks) in evaluating motor performance following opioid administration. For example, a task combining speeded timed response with attentional demands, such as the Stroop Task (Stroop 1935; MacLeod 1991), may be of interest.

The present study demonstrated the feasibility of performing laboratory studies of morphine analgesia in normal volunteers. Specifically, the highest dose of morphine used was sufficient to increase pain tolerance time in the cold pressor task, but it produced side effects similar to those caused by diphenhydramine, the active placebo used in our study. The fact that morphine effect on tolerance time can be observed in the absence of major clinical side effects suggests that it is possible to combine the dose of morphine sufficient to cause analgesia in experimental pain with other proven behavioral methods of pain control.

This study has implications for clinical care. We found that the administration of oral morphine at a dose equivalent to the recommended starting dose for management of moderate to severe cancer pain (Jacox et al. 1994b) and acute postoperative pain (Acute Pain Management Guideline Panel 1992) did not produce significant impairment in motor coordination or simple problem-solving tasks compared with diphenhydramine. There has been some controversy regarding the appropriateness of the size of this dose (O'Neill et al. 1994; Jacox et al. 1994a). The severity of side effects may have been somewhat overstated in response to the publication of AHCPR guidelines for management of cancer pain. Our data document that the spontaneously reported side effects induced by oral morphine are generally comparable in prevalence and severity to those induced by diphenhydramine as reported by opioid-naive normal volunteers. [This is at a dose level of diphenhydramine $(0.357 \mathrm{mg} / \mathrm{kg})$ often prescribed for the common cold]. However, the observed performance deficits in some aspects of the verbal memory test suggest that cognitive and behavioral pain control strategies heavily dependent on memory might be compromised when morphine is used. It will be crucial to extend the present study by investigating how long-term morphine administration affects patients with clinical pain in terms of both pain relief and impairment of memory, motor, and simple cognitive functions.

\section{ACKNOWLEDGMENTS}

This research was supported by Grant No. NS22677 from the National Institutes of Health. Dr. Miroslav Backonja's research is supported by Grant No. NS01365 from the National Institutes of Health. We thank Tito R. Mendoza for his statistical consultation.

\section{REFERENCES}

Acute Pain Management Guideline Panel (1992): Acute Pain Management: Operative or Medical Procedures and Trauma. Clinical Practice Guideline. AHCPR Pub. No. 92-0032. Rockville, MD, Agency for Health Care Policy and Research, U.S. Department of Health and Human Services, Public Health Service

Beardsley JV, Matthews CG, Cleeland CS, Harley JP (1978a): Experimental T-score norms for CA 34 - on the Wisconsin neuropsychology test battery. Unpublished

Beardsley JV, Matthews CG, Cleeland CS, Harley JP (1978b): Experimental T-score norms for CA $35+$ on the Wisconsin neuropsychology test battery. Unpublished

Beecher HK (1959): Measurement of Subjective Responses. New York, Oxford University Press

Buchsbaum MS, Davis GC, Coppola R, Naber D (1981): Opiate pharmacology and individual differences. I. Psychophysical pain measurements. Pain 10:357-366

Casey KL, Minoshima S, Berger KL, Koeppe RA, Morrow TJ, Frev KA (1994): Positron emission tomographic analysis of cerebral structures activated specifically by repetitive noxious heat stimuli. J Neurophysiol 71:802-807

Cleeland CS (1988): Psychological aspects of pain due to cancer. In Abram S (ed), Cancer Pain. Boston, Klower Academic Publishers, pp 33-48

Cleeland CS (1989): Measurement of pain by subjective report. In Chapman CR and Loeser JD (eds), Advances in Pain 
Research and Therapy, Volume 12: Issues in Pain Measurement. New York, Raven Press, pp 391-403

Cooper BY, Vierck C] Jr, Yeomans DC (1986): Selective reduction of second pain sensations by systemic morphine in humans. Pain 24:93-116

Davison LA, Reitan RM (1974): Clinical neuropsychology: Current status and applications. Washington, Winston

Derogatis, LR (1983): SCL-90-R: Administration, scoring and procedures manual-II for the $R$ (evised) version and other instruments of the psychopathology rating scale series. 2nd ed. Towson, MD, Clinical Psychometric Research

Glare PA, Walsh TD (1991): Clinical pharmacokinetics of morphine. [Review]. Therap Drug Monit 13:1-23

Glynn C, Dawson D, Sanders R (1988): A double-blind comparison between epidural morphine and epidural clonidine in patients with chronic non-cancer pain. Pain 34: $123-128$

Gracely, RH, Dubner R, McGrath I'A (1979): Narcotic analgesia: Fentanyl reduces the intensity but not the unpleasantmess of painful tooth pulp sensations. Science 203:1261-1263

Gracely RH, Dubner R, McGrath PA (1982): Fentanyl reduces the intensity of painful tooth pulp sensations: Controlling for detection of active drugs. Anest Analg 61:751-755

Gracely RH (1991): Experimental pain models. In Max MB, Portenoy RK, and Laska E (eds), Advances in Pain Research and Therapy, Volume 18. New York, Raven Press, pp 33-47

Gronwall DM (1977): Paced auditorv serial-addition task: A measure of recovery from concussion. Percep Motor Skills $4+367-373$

Heaton RK, Grant I, Matthew's CG (1994): Comprehensive norms for an expanded Halstead-Reitan battery: Demographic corrections, research findings, and clinical applications. Odessa, FL, Psychological Assessment Resources

Hilgard ER, Hilgard JR (1983): Hypnosis in the relief of pain. 2nd ed. I.os Altos, CA, William Kautman, Inc.

Hodes RL, Howland EW, Lightfoot N, Cleeland CS (1990): The effects of distraction on responses to cold pressor pain. Pain 41:109-114

Jacox A, Carr DB, Payne R (1994a): Treating cancer pain [letter]. N Eng / Med 331:201

Jacox A, Carr DB, Payne R, et al. (1994b): Management of Cancer Pain. Clinical Practice Guideline No. 9 AHCPR Publication No. 94-0592, Rockville, MD, Agency for Health Care Policy and Research, U. S. Department of Health and Human Serrices, Public Health Service?

Jones SF, McQuav HJ, Moore RA, Hand CW (1988): Morphine and ibuprofen compared using the cold pressor test. Pain 34:117-122

Kaiko RF, Wallenstein SL, Rogers AG, Grabinski PY, Houde RW (1981): Analgesic and mood effects of heroin and morphine in cancer patients with postoperative pain. $>$ Eng J Med 304:1501-1505

Kerr B, Hill H, Coda B, Calogero M, Chapman CR, Hunt E, Buffington V, Mackie A (1991): Concentration-related effects of morphine on cognition and motor control in human subjects. Neuropsychopharmacology 5:157-166

Lasagna L, I on Felsinger JM, Beecher HK (1955): Drug-induced mood changes in man. JAMA 157:1006-1020
Lezak MD (1983): Neuropsychological assessment. 2nd ed. New York, Oxford University Press

MacLeod CM (1991): Half a century of research on the Stroop effect: An integrative review [review]. Psychol Bull 109: $163-203$

Merkatz RB, Temple R (1993): Women in clinical trials. FDA Med Bull 23:2-4

Nowlis V (1965): Research with the Mood Adjective Check List. In Tomkins SS and Izard CE (eds), Affect, cognition, and personality: empirical studies. New York, Springer Pub. Co. pp 352-389

O'Neill, WM, Chambers EJ, Fallon MT (1994): Treating cancer pain [letter]. N Eng J Med 331:200-201

Parry WL, Smith GM, Denton JE (1972): An electric-shock method of inducing pain responsive to morphine in man. Anest Analg 51:573-578

Posner J, Telekes A, Crowley D, Phillipson R, Peck AW (1985): Effects of an opiate on cold-induced pain and the CNS in healthy rolunteers. Pain 23:73-82

Price DD, Von der Gruen A, Miller J, Rafii A, Price C (1985): A psychophysical analysis of morphine analgesia. Pain $22: 261-269$

Smith GM, Egbert LD, Markowitz RA, Mosteller F, Beecher HK (1966): An experimental pain method sensitive to morphine in man: The submaximum effort tourniquet technique. J Pharmacol Exp Ther 154:324-332

Stroop JR (1935): Studies of interference in serial verbal reactions. I Exp Psychol 18:643-662

Syrjala KL (1993): Integrating medical and psychological treatments for cancer pain. In Chapman CR and Foley KM (eds), Current and Emerging Issues in Cancer Pain: Research and Practice. New York, Raven Press, pp 393$4(19$

Wiens AN, McMinn MR, Crossen JR (1988): Rey AuditoryVerbal Learning Test: Development of norms for healthy young adults. Clin Neuropsychol 2:67-87

Wolff BB, Kantor TG, Jarvik ME, Laska E (1966): Response of experimental pain to analgesic drugs. 1. Morphine, aspirin, and placebo. Clin Pharmacol Ther 7:224-238

Wolskee PJ, Gracely RH, Sayer MJ, Dubner R (1981): Effect of morphine on experimental pain and measures of clinical pain in chronic pain patients. Pain (suppl) 1:S155

World Health Organization (1986): Cancer pain relief.

Yang IC, Clark WC, Ngai SH, Berkowitz BA, Spector S (1979): Analgesic action and pharmacokinetics of morphine and diazepam in man: An evaluation by sensory decision theory. Anesthesiology 51:495-502

Zacny JP, Lichtor JL, Thapar P, Coalson DW, Flemming D, Thompson WK (1994): Comparing the subjective, psychomotor and physiological effects of intravenous butophanol and morphine in healthy volunteers. J Pharmacol Exp Ther 270:579-588

Zelman DC, Howland EW, Nichols SN, Cleeland CS (1991): The effects of induced mood on laboratory pain. Pain $46: 10 \overline{5}-111$ 